\title{
versants
}

\section{Ser hispanista. ¿Por qué?}

David T. GIES ${ }^{1}$

Universidad de Virginia, EE.UU.

\begin{abstract}
Por qué se inspira un individuo no hispánico en convertirse en lo que llamamos "hispanista" (persona que se dedica al estudio de la lengua, literatura y cultura de países hispanohablantes)? Las razones son múltiples y con frecuencia sorprendentes. Algunos descubren su vocación temprano, otros más tarde en la vida. Unos estudian la historia de la lengua o la lingüística mientras otros investigan la literatura medieval o la contemporánea, el cine o la historia, los dramaturgos o los poetas, la novela o el refrán. Ser "hispanista" es ser "agente cultural" encargado de estudiar, enseñar y promocionar la cultura del mundo hispánico.
\end{abstract}

Keywords: Hispanista, agente cultural, profesión, hispanismo.

El curioso fenómeno del individuo que decide dedicar su vida profesional (y, en muchos casos, su vida personal también) al estudio de otra cultura que no es la suya no tiene explicación fácil.

Que una persona se enamore de la gente, los sonidos, el arte, la historia, la gastronomía, la música, la literatura -ah, siempre la literatura- de otro país desafía la lógica y la tradición. La gente suele estudiar y apreciar lo suyo, aprender $s u$ historia, $s u$ lengua y su cultura para conocerlas más a fondo o para alardear de su importancia por encima de la historia, lengua o cultura de sus vecinos. No parece nada natural ni normal que en un momento dado de su vida un individuo abandone (o minimice) su propia cultura -del país de nacimiento o país de residencia- para profundizar ("chapuzarse", como diría Unamuno) en otra. Pero así es el fenómeno de "ser hispanista".

En múltiples países del mundo y por muy diversas razones, hay miles de individuos que se declaran "hispanistas". Desde Corea, Japón, Taiwán y China hasta la India, Canadá, Gran Bretaña, Europa, Estados Unidos, Egipto y el resto de África, toda Latinoamérica y los rincones más diversos de la Tierra, se estudia "lo hispánico" (lengua, cultura, historia, literatura).

Pero, ¿qué es "lo hispánico"? ¿Qué significa "ser hispanista"? ¿Qué es un "Hispanista"? ¿Qué motiva a una persona a declararse "hispanista"? ¿Qué

I David T. Gies (Universidad de Virginia, EEUU. Presidente de Honor AIH), Presidente de mesa. Con la colaboración de Urszula Aszyk (Universidad de Varsovia, Obozna, Polonia), Seungwook Baik Woo (Universidad de Corea); Trevor J. Dadson (Presidente de la Asociación de Hispanistas de Gran Bretaña e Irlanda. Universidad Queen Mary, Londres, Reino Unido); Nagwa Gamal Mehrez (Universidad de Ain Shams. Presidenta de la Asociación de Hispanistas Árabes y de la Asociación de Hispanistas de Egipto); Minni Sawhney (Universidad de Delhi, India); Luisa Shu-Ying Chang (Universidad Nacional de Taiwán). 
valor tiene ser "hispanista"? ¿Cómo ven los "hispanistas" el objeto de su estudio, el mundo hispánico?

En el Oxford English Dictionary se encuentra una definición de "hispanista": «uno versado en, o dedicado a, la lengua española», una definición documentada por primera vez en el Webster's Dictionary americano en i834. Pero "hispanisme" ya se usó en la Académie Française en el siglo XVIII ("tournure propre à la langue espagnole»), aunque "hispaniste / hispanisant" es invención del siglo xx. Pero, obviamente, un hispanista no necesita pertenecer a la academia o investigar o enseñar en una universidad. Necesita ser, pura y sencillamente, lector.

Algunos hispanistas descubren su vocación temprano, de niños, en casa de unos padres que mantienen (o intentan mantener) la cultura y la lengua de su país materno. Estos individuos pueden ser hispanohablantes, españoles exiliados o refugiados, ubicados en países extranjeros por razones políticas, personales o económicas. El famoso exilio de los republicanos de la guerra civil española empobreció España, pero enriqueció enormemente los muchos países que recibieron a los exiliados, tanto en Europa como en América. En EE.UU., la enseñanza del español recibió un gran ímpetu con la llegada de grandes profesores e intelectuales como Américo Castro, Pedro Salinas, Ramón J. Sender, Vicente Llorens, Antonio Rodríguez Moñino, José Fernández Montesinos, Juan Ramón Jiménez, Jorge Guillén y otros. En Francia y Gran Bretaña, lo mismo. (Hemos escrito "profesores" arriba porque la gran mayoría de los profesores de español, exiliados o no, eran hombres. «Todos mis profesores, ¡todos!, fueron hombres», en palabras de una hispanista. Pero las pocas profesoras que en los años I960 habían ganado cátedras en las universidades norteamericanas y europeas marcaron profundamente las trayectorias de dos generaciones de hispanistas [mujeres]).

Algunos hijos de aquellos exiliados llegaron a ser hispanistas, escritores o profesores de español en el extranjero. Individuos exiliados por razones económicas descubrieron que podían ganarse el pan dando clase en una escuela secundaria o en una universidad. Otros muchos llegaron a ser hispanistas por casualidad, casi por accidente, después de un encuentro con un hispano, un viaje a España o Latinoamérica, la lectura de una novela que les apasionó, el primer encuentro con una pintura de Velázquez, Goya o Picasso, o al ver una película de Buñuel, Saura o Almodóvar. ¿Qué hispanista no recuerda ese primer momento de delicia al saborear una tortilla de patata o una croqueta de jamón? ¿De participar en una conversación animada con amigos en un café, quizás a las dos o tres de la madrugada? ¿De haber terminado la lectura de una novela inspiradora o una poesía conmovedora? ¿De haber sentido el traqueteo de las ruedas de un tren en un viaje nocturno de Madrid a Cáceres, o de Sevilla a Granada? 
¿Quién no se ha sentido transportado al escuchar por primera vez versos como los siguientes?:

«Miré los muros de la patria mía...»

«¿Qué es poesía? dices, mientras clavas / en mi pupila tu pupila azul...»

«A las cinco de la tarde. / Eran las cinco en punto de la tarde.»

«Que toda la vida es sueño / y los sueños, sueños son.»

«En una noche oscura, / con ansias, en amores inflamada...»

«Que es mi barco mi tesoro, / que es mi dios la libertad...».

Ese contacto tiene importancia, no sólo para el individuo sino también para España. Como escribe Anna Caballé:

La importancia del hispanismo en la internacionalización de la lengua y la cultura hispánicas [...] y en las consecuencias que su proyección genera es fundamental para España. Es un hecho que se debe en buena parte a la labor de quienes asumieron y asumen vocacionalmente su tarea de comprender, estudiar y difundir nuestras señas de identidad (2014: 7).

Evidentemente, el hispanismo no se ubica en una sola parte, geográficamente hablando, sino que está en los cerebros y los corazones de todos sus practicantes. Todos nosotros somos el hispanismo, estemos donde estemos. El hispanismo es una entidad fluida, mental, emocional, científica y flexible (adjetivos que evocan el método artístico de Salvador Dalí). Como cómicos de la lengua, nos vamos representando y publicando nuestras obras por el mundo. Como Don Quijote, vamos batallando contra los errores, molinos de viento y, a veces, gigantes, en nuestro deseo de comprender más a fondo las «señas de identidad» señaladas por Caballé.

Esas señas - tan misteriosas, tan intangibles, tan atractivas- son las que llaman la atención de los hispanistas. Si se intenta contestar la pregunta, “Qué es ser hispanista?", primero se tendría que contestar la pregunta, “Qué es ser hispano?” Pero, claro, esa es una pregunta que no tiene respues- 
ta sencilla. No existe una respuesta universal y única porque no es posible definir toda una cultura, una etnia, una historia, o una lengua en términos sintéticos y comprensibles.

Por eso, el "ser hispanista” tiene múltiples formas. “¿Qué es ser hispanista?” tiene múltiples respuestas. ¿¿Cómo llegó Vd. a ser hispanista?” tiene múltiples contestaciones.

Durante nuestra vida, es decir, durante los últimos 50-80 años, hay países que ya tenían una estructura colegial y universitaria de la enseñanza de la lengua, literatura y cultura hispanas.

En los EE.UU., ya a finales del siglo XVIII Tomás Jefferson reconoció la importancia del estudio de la lengua española. El futuro presidente escribió a su sobrino lo siguiente en I789: «Presta gran atención a esta lengua e intenta adquirir un conocimiento preciso de ella. Nuestras futuras relaciones con España e Hispanoamérica harán que el español sea una adquisición valiosa. La historia antigua de esa parte de América está escrita en ese idioma»² (20II: 238). Jefferson, al fundar la Universidad de Virginia, creó la primera cátedra de Lenguas Modernas, en la que se enseñó entre ellas, naturalmente, el español. Pocos años después, intelectuales como Henry Wadsworth Longfellow y George Ticknor reconocieron la importancia del estudio del español y establecieron otras cátedras en las universidades más prestigiosas del país. Walt Whitman, poeta del famoso libro, Leaves of Grass (Hojas de hierba), también hizo hincapié en la importancia de la cultura e historia de España y su relación con la cultura e historia de América: «A esa identidad compuesta americana del futuro, el carácter español va a añadirle algunos de los elementos más necesarios. No hay ninguna gente que demuestre mayor respeto histórico, mayor religiosidad y lealtad, mayor patriotismo, mayor decoro, valentía, gravedad y honor»³ (I964: 552). Una organización dedicada exclusivamente al estudio de lo hispánico -the American Association of Teachers of Spanish and Portuguese-se fundó en I9I7 y sigue en pie con miles de miembros y actividades anuales.

Gran Bretaña siempre ha tenido un robusto respeto por lo hispánico (la primera traducción de un libro español al inglés fue la Celestina en I525; el Quijote solo tuvo que esperar siete años después de su publicación para ser accesible a los lectores anglohablantes (traducido por Thomas Shelton, primera parte en I6I2, segunda parte en I620); se puede decir que son los británicos los que convirtieron al Quijote en un texto universal, leído más fuera de

2 «Bestow great attention on this, and endeavor to acquire an accurate knowledge of it. Our future connections with Spain and Spanish America will render that language a valuable acquisition. The ancient history of that part of America, too, is written in that language».

3 "To that composite American identity of the future, Spanish character will supply some of the most needed parts. No stock shows a grander historic respect — grander in religiousness and loyalty, or for patriotism, courage, decorum, gravity and honor». 
España que en su propio país de publicación. Numerosos viajeros británicos documentaron sus viajes por la península ibérica desde el siglo Xvi hasta el siglo xIx. Son los hispanistas británicos los que crearon varias generaciones de notables estudiosos, al insistir en que la historia de la península, junto con su literatura y cultura, tenía tanto interés y tanta importancia como la de otros países del norte de Europa.

En Alemania, la fascinación con lo romántico -y la identificación de España como el país romántico por excelencia- floreció en los primeros años del siglo xix. Sabemos que Ferdinand Wolf compartió la pasión de Agustín Durán por el gran romancero español.

En Francia notables dramaturgos como Corneille conocieron las obras del Siglo de Oro español y, años después, varias generaciones de viajeros, novelistas y pintores descubrieron la cultura de su vecino sureño. La Carmen de Mérimée se ha convertido - con la ayuda de Bizet- en símbolo de la cultura española en el extranjero (una opinión muy controvertida, pero esa es otra historia).

El hispanismo en Rusia recibió su más fuerte ímpetu con la profunda influencia que ejerció la novela de Cervantes en novelistas realistas como Dostoyevsky, Tolstoy o Turgenev. Pero la Asociación Rusa de Hispanistas es un fenómeno mucho más tardío; se estableció en 1994.

Giambattista Conti y Pietro Napoli Signorelli (amigos de Nicolás Fernández de Moratín) consolidaron el interés italiano en lo español a finales del siglo XVIII.

Asia y el Norte de África (sobre todo en Egipto) han tenido un hispanismo robusto y activo desde hace muchos años.

Pero hay otros lugares del mundo en los que el español tuvo poco impacto al principio (o, mejor dicho, en que el estudio del español como tema académico se desarrolló a un ritmo menos acelerado que en otros países). Lo románico, como se entendía en los colegios o las grandes universidades occidentales, incluía -en el siglo xIx y gran parte del xx-principalmente el francés y el italiano, pero no el español. Este fue el caso en muchos colegios británicos, en los que dominaban el francés y el alemán. En otros países, por ejemplo en Polonia, país en que los estudios hispánicos se iniciaron en el seno de los estudios románicos a finales del siglo XIX, el español como asignatura se introdujo en el programa universitario tan solo en la segunda mitad del siglo xx, aunque hubo excepciones (en la Universidad de Varsovia se lo enseña desde 1917). Ni siquiera existían departamentos de filología española en numerosísimas universidades mundiales.

Muchos alumnos descubren la cultura hispánica a través de la lengua. Es decir, algunos jóvenes comienzan a estudiar el idioma en la escuela primaria (otros tienen que esperar hasta el colegio o incluso hasta comenzar la carrera universitaria) y a partir de ahí entran en el rico y complejo mundo 
de la literatura y cultura. El interés por la filología provoca con frecuencia un deseo de profundizar en la historia de la lengua, en su estructura, en su uso, en sus ricas expresiones culturales. Muchas veces es un profesor o una profesora que reconoce un talento especial en un alumno y así le anima a seguir esos estudios. $\mathrm{O}$, es un profesor que abre el camino hacia la literatura española al incluir un verso, un poema, una novela o un drama en una asignatura de "literatura comparada" o "literatura europea". El ser hispanista es abrazar todo un contenido humanístico, no solo una lengua.

Pero también es la lengua. Hay hispanistas que confiesan que se enamoraron de la lengua española por encima de todo. El sonido, el ritmo, la rima, el acento, el calor del idioma... eso primero, y luego un trozo de un poema, una bella frase de una comedia, un cuento. "Quiero más, siempre quiero más."

Un hispanista no hispanohablante también se puede acercar a lo español en su propia lengua. ¿Cuántos hemos leído, por ejemplo, el Quijote -o los versos de Pacheco o los cuentos de Borges- primero en nuestra lengua materna (inglés, chino, hindú, francés, italiano, árabe) antes de descubrir el original en español? Con frecuencia nos descubrimos a nosotros mismos en la literatura, nos identificamos con los héroes o heroínas de las obras que estamos leyendo. Queremos corregir injusticias, como Alonso Quijano. Queremos expresar una pasión, como Neruda. Queremos combatir la opresión, como el pueblo de Fuenteovejuna. Queremos reírnos de la estupidez política, como Fígaro. Queremos entender lo que es ser niña en la España de Franco, como la protagonista de Entre visillos de Carmen Martín Gaite. Queremos desafiar las injusticias cósmicas, como don Álvaro. Esas experiencias vitales se encuentran en las páginas de los libros que leemos, que nos hacen leer los profesores, que queremos leer.

Pero hay más. Sin duda, una de las experiencias más profundas en la trayectoria de llegar a ser hispanista es el contacto directo con el mundo hispánico. Una y otra vez los hispanistas recuerdan ese primer contacto, ese primer viaje a Madrid o Bogotá o Valencia o Buenos Aires, saboreando el clima, los colores, la famosa hospitalidad hispana, el arte, los monumentos, la sangría y las tapas. La generosidad espiritual y material de los hispanos ha captado a generaciones de jóvenes que llegan a tierras lejanas en busca de una experiencia "extranjera". Esa "extranjeridad" pronto se convierte en "intimidad" porque el ritmo de la vida en el mundo hispánico seduce, capta, divierte y fascina. Los "hispanistas" de los siglos anteriores (más bien, el XVIII y el xix) ya habían experimentado esa fascinación y sus memorias, novelas y libros de viajes iniciaron toda una profesión que llegaría a ser llamada "hispanismo".

No todo son rosas (o croquetas). A pesar de lo atractivo de ese contacto con una cultura foránea, la ruta hacia el hispanismo, hacia ser hispanista-como 
la de don Quijote y Sancho- no es siempre fácil. Existen obstáculos al deseo de ser hispanista: la falta de financiación y becas para los jóvenes que quieren comenzar una carrera, la creencia en algunas partes de que los estudios hispánicos son tema "marginal", las distancias entre algunos países y el objeto de estudio (España), los costos de una estancia en España, el difícil acceso a algunas materias necesarias para la elaboración de un estudio científico, etc. Algunos hispanistas han comentado la falta de información sobre la profesión de "ser Hispanista", es decir, sí, se enseñó la lengua y la literatura, pero hace dos generaciones se comentó poco otra información importante que hoy en día parece esencial si uno aspira a ganar una oposición o una cátedra universitaria: cómo publicar (y dónde), cómo participar en congresos (y cuándo), o cómo colaborar con los colegas (y con quién).

Además, puede ser un impedimento la lengua misma. No es fácil el español, especialmente para la gente que no tiene tradición de hablar o aprender idiomas que proceden de la familia indo-europea de lenguas, o, más concretamente, de las lenguas que tienen su base en el latín. La morfología y sintáxis del español son complejas, el uso de tildes y verbos irregulares a veces confunden a los alumnos (¿yo sé? ¿yo sabo?), el acento es difícil (¿castellano o español americano? ¿seseo?), la riqueza léxica puede ser abrumadora, por no mencionar la labor de los historiadores de la lengua, que buscan los orígenes de las palabras y documentan su uso a través de los siglos.

A pesar del notable hecho de que lo hispánico va en alza en la gran mayoría de las universidades mundiales, hoy en día se nota una falta de compromiso político y una disminución de la financiación. Los alumnos quieren aprender el español, pero en determinados casos los recursos se van desviando hacia otras áreas de estudio. Las humanidades son percibidas en algunas partes como menos importantes que las ciencias, la ingeniería o el comercio. Se dice a veces que hay más trabajos y trabajos mejor pagados en esos campos que en las humanidades (pero los datos no apoyan tales observaciones). De ahí se sigue otra carencia: la falta de profesores de instituto que puedan animar a la siguiente generación a estudiar el español y hasta llegar a ser hispanistas (en Gran Bretaña, por ejemplo, se calcula que faltan casi 4000 profesores de lenguas a nivel secundario -la mayor parte de ellos para el español-). Sin profesores, no hay alumnos, decae la asignatura, se atrofia el estudio del español y, por fin, desaparecen los hispanistas. Esta es una visión apocalíptica, claro está, pero es una realidad de la que tenemos que estar atentos y prepararnos para ella. Es un círculo vicioso que puede resultar en una disminución substancial del hispanismo. Necesitamos promocionar mejor el valor intelectual, espiritual, social y emocional de ponernos en contacto con otras culturas. 
¿Qué hacer? Como Don Quijote, tenemos que salir no al campo, sino al aula, para «deshacer agravios, enderezar tuertos, enmendar sinrazones y mejorar abusos», además de cultivar la pasión de nuestros alumnos.

Por eso, de alguna forma, "ser hispanista" es ser "agente cultural" encargado de estudiar, enseñar y promocionar la cultura del mundo hispánico. También es saber transmitir a estas regiones las noticias sobre la recepción de la cultura hispánica en otros países. Visto desde esta perspectiva, "ser hispanista" es una ocupación bicéfala, o quizás mejor dicho, doble: es investigar $y$ enseñar, recibir $y$ dar, ser pasivo $y$ activo, ver las cosas desde dentro $y$ desde fuera -todo a la vez.

Muchos hispanistas son "hispanistas por casualidad". Es decir, no tenían nunca un gran plan, un mapa profesional que les llevara a convertirse en hispanistas. Cuando uno habla con hispanistas hoy, hay frases que se repiten: "por si acaso", "fortuito", "suerte", "al azar", "lo no intencionado", "por casualidad", etc. Muchos llegamos a ser hispanistas no por un plan concertado, un mapa intelectual, una determinación a seguir una carrera, sino "por casualidad" después de un contacto con España, con su gente, con su arte, con su literatura, con su historia, con su comida. ("Escogí el español al azar", en palabras de una distinguida hispanista). Jóvenes colegiales y universitarios suelen ser poco pragmáticos, es decir, no piensan claramente en el futuro, sino que disfrutan del momento. Si ese momento contiene algo que les capta la atención, que les conmueve, que les inspira, entonces ven la posibilidad de construir una vida profesional. Con frecuencia fue un contacto rápido, un momento "de amor", un flechazo pirotécnico, algo semejante a lo que explica don Juan Tenorio al ver a su doña Inés:

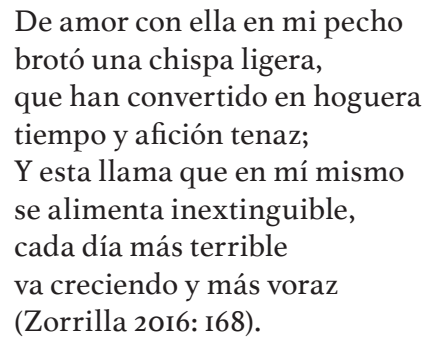

También surgen otras palabras -"gusto", "placer", "disfrute", "amor", "privilegio" y "honor"- palabras que captan la intensa sensación de agradecimiento que sentimos al poder dedicar nuestra vida profesional al estudio de una cultura tan compleja como es la hispánica y de poder transmitir ese placer, a través de la enseñanza, la investigación y la publicación de libros y artículos, a otras generaciones futuras. Hablar de la literatura española con los jóvenes, pasar tiempo en un país hispanohablante, buscar documentos 
en los archivos, profundizar en problemas culturales enormemente ricos. ¿Por dónde empezar? ¿Dónde terminar?

Según los que ejercen esta profesión, los placeres de ser hispanista son innumerables. Los hispanistas internacionales comentan la delicia de descubrir nuevas obras literarias, de ver iluminadoras exposiciones de arte y arquitectura no solo en España sino también en sus países (exposiciones itinerantes), de pensar larga y profundamente sobre cuestiones complicadas y matizadas, de dialogar con antiguos y nuevos amigos, de saborear un café con leche o un chocolate con churros, de meditar sobre la larga, inquietante y noble historia del país, de intentar descifrar los infinitos misterios de la cultura española. Es, para su deleite, el cuento de nunca acabar.

Ser hispanista no es recibir un salario, sentarse cuarenta horas semanales en un despacho, exponer delante de un grupo de jóvenes impresionables las "glorias" de la literatura hispánica. No, es sentir el calor de la lengua, la pasión de la palabra, la emoción de la belleza literaria. Nuestro deber como hispanistas es comunicar que el mundo intelectual es una vocación, no es un sueldo mensual. Es convencer a los jóvenes -y al mundo entero- de que el español importa, que las Humanidades revelan quiénes somos y de dónde venimos; que la cultura es relevante. Está claro que somos más cosmopolitas y mejores "ciudadanos del mundo" al profundizar en la cultura hispanohablante. Es un privilegio tener amigos en todos los rincones del mundo, compartir diversas ideas intelectuales con ellos y ganar oportunidad de reflexionar sobre el valor de la vida humana.

Y lo es. Lo bonito de ser hispanista es que el hispanismo sigue cambiando, enriqueciéndose con nuevos temas (por ejemplo, la incorporación de estudios sobre el cine o la televisión, el turismo o la gastronomía, el género, el medioambiente, la discapacidad, áreas que atraen a nuevos alumnos y provocan nuevos acercamientos teóricos) mientras mantiene el interés en lo clásico (lo antiguo, lo tradicional, llámese como se llame).

Para terminar, citaremos las palabras de un gran hispanista que resume algo de que todos los hispanistas podríamos alardear: «He podido dedicar toda mi vida a una cultura que no es la mía, pero que amo como si lo fuera. Lo único que puede hacer un hispanista es intentar acercarse todo lo posible a la cultura hispánica, sabiendo que nunca va a llegar del todo, pero que tiene la ventaja de poder ver las cosas "desde la otra ribera"». 


\section{Bibliografía}

Caballé, Anna, «Veintiuna autobiografías inesperadas», en ¿Por qué España? Memorias del hispanismo estadounidense, eds. Anna Caballé Masforroll \& Randolph D. Pope, Barcelona, Galaxia Gutenberg, 2014.

Jefferson, Thomas, The Writings of Thomas Jefferson, Vol. 2, ed. H. A. Washington, Cambridge, Cambridge University Press, $20 \mathrm{II}$.

Whitman, Walt, Prose Works I892. Vol.2, ed. Floyd Stoval, Nueva York, New York University Press, I964.

Zorrilla, José, Don Juan Tenorio, ed. David T. Gies, Madrid, Castalia, 2016. 